\title{
Practices of Implementing Functional Adult Education Program in Robe and Goba Cities of Bale Zone
}

\author{
Ayele Kumsa Hordofa* \\ College of Education and Behavioral Studies \\ Department of Adult Education and Community Development, PO box 247, Madda Walabu University \\ Demissie Korsa \\ College of Education and Behavioral Studies, PO box 247, Madda Walabu University
}

\begin{abstract}
The purpose of this study was to identify practices of implementing Functional Adult Education program in Goba and Robe cities of Bale Zone. Descriptive Survey design with mixed, qualitative and quantitative approaches was employed. Questionnaires, interviews and document analysis were used as data gathering instruments. The populations of the study were 60 facilitators (Newly hired $10^{\text {th }}$ complete and formal school teachers) who work at Robe Town 4 centers and Goba town 2 centers. From the 60 facilitators, 30(50\%) were selected proportionally through simple random sampling technique. Whereas, 4 experts $(\operatorname{Goba}(2), \operatorname{Robe}(2))$ education offices and 4 Supervisors (Goba(2),Robe(2)) of Functional Adult Education Centers were selected for interview sessions through purposive sampling techniques. Annual reports and documents were used as secondary source. The data collected through questionnaire, interview and document review were analyzed through frequency, percentage, and mean value and thematically through narrative respectively. Results indicated that, the roles of supervisors and facilitators were not accomplished at high level of performance. In addition, it has set out and was judged by both facilitator respondents and interviewees that, lack of managerial skills, lack of community participation, lack of training and professional support, lack of monitoring and evaluation, lack of accountability and responsibility were some of the factors that highly affect the implementation of Functional Adult Education program. Thus, from the finding it is possible to conclude that the implementation of program in both administrative cities were not carried out according to the principles and guide lines of FAL program. Therefore, selection and training of facilitators, awareness creation and Institutional supervision should be carried out according to the principles and guide lines of Functional Adult Literacy program.
\end{abstract}

Keywords: Adult Education, Facilitators, Functional Adult Literacy, Implementing Practices DOI: $10.7176 / \mathrm{JEP} / 10-34-04$

Publication date: December $31^{\text {st }} 2019$

\section{Heading 1}

\subsection{Background of the study}

Education remains the biggest instrument for academic progress, social mobilization, political survival and effective national development of any countries (Usman, Yunusa Dangara, 2015). According to Mari Yasunaga, (2014), non-formal as a part of education is one such pathway.

Functional adult literacy as part of non formal education is the newly introduced program of adult learning system including the practical life experience or real life style of the adult learner. (Tadesse Abera 2019). Although policy documents (for example, Education and Training Policy 1994,) state the importance of adult education for the attainment of other development agendas including the education of children, its provision and quality remained low. The German Adult Education Association (dvv) and its Institute for international Cooperation (IIZ, since $2007 d v v$ international) has helped a number of African countries including Ethiopia developing or strengthening their adult education system over the years.(Sandhaas, Bernd 2009)

The government Ethiopia formulates MOU among different sectors in order to achieve the practicality of the program. For instance, Samuel Asnake (2012), further recited that, the development of National Adult Education Strategy (2008) that opened the way for different sectors to rethink their role in adult education is a good example. However, the implementation practice failed to give it adequate attention. (Global campaign for education, 2005:9). It is particularly important in developing countries like Ethiopia and Turkey where formal education has not reached a significant proportion of the adult population, particularly in the rural areas.

Even though, MoE prepared strategy, programs, different frameworks, guidelines, training manuals text books for both Rural and Urban Adult learners, its implementation practices still seems weak. Genet (2014) confirmed that, in Ethiopia, Functional Adult Literacy still to be seen as a secondary issue and hence, is far from being achieved. The same ideas have been reflected by researchers in the area. For instance, According to Sisay Awgichew \& Yilfashewa Seyoum (2017) recently, the government of Ethiopia has been working to address more than 19 million illiterates across the country. However, the practices and challenges are not yet investigated 
in-depth. Similarly, According to Mulugeta (2002), in Kifle Bidika, (2016), the region Woreda education office staff, the literacy teachers and even literacy participants has correct understanding on the basic concepts of the strategy document. However, the knowledge couldn't be able to maximize the implementation practices and the rate of adults' participation.

Genet, (2014) do not critically investigate the causality and extent of all these problems for policy makers, program designer and implementers as a gap. Furthermore, the practice of adult education program is not checked, and research based solution for the challenge encountering the program has not yet recommended for further improvements" (Sisay and Yilfashewa, 2017) in (Tadesse Abera 2019). As a result, the issue of Adult education implementation practices in the Oromia Region particularly in Bale Zone selected Towns are yet under the problems. That is why the researchers of this study are more interested to fill the gap existing and undertook further study on the practice of implementing FAE program in Robe and Goba Cities of Bale Zone. It was also this situation that gave justification to the effort made to examine the current practice and possible explanatory factors regarding the implementation of FAL program in Goba and Robe administrative cities. Thus, Based on the objective, this study attempts to answer the following basic questions.

1. What do the practices of FAL look like in Goba and Robe administrative cities of Bale Zone?

2. How is the functional adult literacy program managed?

3. What are the challenges related to the practice of FAL in Goba and Robe cities?

\subsection{Materials and Methods}

The main objective of this study is to investigate the Practices of Implementing Functional Adult Education Program In Robe and Goba Cities of Bale Zone. To attained the desired objective, mixed both quantitative and qualitative approaches were used. Mainly the choice of the research design is based on the research problem in the study and the personal experiences of the researcher (Creswell, 2008).

\subsection{Data gathering Instruments Questionnaires}

Two sets of questionnaires were first prepared in English and the Afan Oromo versions were distributed to the facilitator respondents to make them more comprehensible. The questionnaires contained both closed-ended and open-ended items. Most of the closed-ended items were constructed in the form of multiple choices while the open-ended questions were prepared in a form of that enable to collect the respondents' suggestions, comments and recommendations.

\section{Interview}

In this study predetermined questions were used with both towns FAL Experts and supervisors to get in depth information about the practices of implementing Functional Adult Education program. Patton, (2002) in Rahel Gashaw (2014) explained that, interview was used because of its flexibility. It allowed depth to be achieved by providing the opportunity on the part of the interviewer to probe and expand interviewee's responses. The interview was conduct on a face-to-face basis.

\subsection{Population, sample and sampling technique}

The populations of the study were 60 facilitators (Newly hired $10^{\text {th }}$ complete and formal school teachers) who work at Robe Town 4 centers and Goba town 2 centers. From the 60 facilitators, 30(50\%) were selected proportionally through simple random sampling technique as shown bellow.

Table 1: Size of facilitators Population.

\begin{tabular}{|l|l|l|l|l|}
\hline Participants & Town & Population & Sample & Sampling techniques \\
\hline \multirow{4}{*}{ Facilitators } & Robe & 40 & 20 & \multirow{3}{*}{ simple random sampling } \\
\cline { 2 - 4 } & Goba & 20 & 10 & \\
\cline { 2 - 4 } & total & 60 & 30 & \\
\hline
\end{tabular}

In addition, 4 experts (Goba(2),Robe(2)) education offices and 4 Supervisors (Goba(2), Robe(2)) of Functional Adult Education Centers were selected for interview sessions through purposive sampling techniques. Annual reports and documents were used as secondary source.

\section{Methods of data analysis}

Depending on the nature of the collected data through questionnaires and interviews, different statistical techniques were employed in the study. The quantitative data were analyzed in descriptive ways using percentile and mean by employing SPSS software version 20. While the qualitative data were narrated qualitatively using words, phrases, statements and paragraphs obtained from interviewees and open-ended questions. Hence, the qualitative data was used as the complement of the quantitative data. 


\section{Results and Discussion}

Table2. Background information of facilitators Experts and supervisors

\begin{tabular}{|c|c|c|c|c|c|c|c|}
\hline \multirow[t]{2}{*}{ Item } & \multirow[t]{2}{*}{ Categories } & \multicolumn{2}{|c|}{ Facilitators } & \multicolumn{2}{|c|}{ Experts and supervisors } & \multicolumn{2}{|c|}{ Total } \\
\hline & & $\mathrm{f}$ & $\%$ & $\mathrm{f}$ & $\%$ & $\mathrm{f}$ & $\%$ \\
\hline \multirow[t]{3}{*}{ Sex } & Male & 23 & 76.7 & 6 & 75 & 29 & 76.3 \\
\hline & Females & 7 & 23.3 & 2 & 25 & 9 & 23.7 \\
\hline & Total & 30 & 100.0 & 8 & 100 & 38 & 100.0 \\
\hline \multirow[t]{3}{*}{ Age } & $20-25$ & 25 & 83.3 & 2 & 25 & 27 & 71.1 \\
\hline & $26-30$ & 5 & 16.7 & 4 & 50 & 9 & 23.7 \\
\hline & Above 30 & & 0.0 & 2 & 25 & 2 & 5.3 \\
\hline \multirow[t]{4}{*}{ Educational level } & 10th complete & 15 & 50.0 & & 0 & 15 & 39.5 \\
\hline & 12th complete & 3 & 10.0 & & 0 & 3 & 7.9 \\
\hline & diploma & 12 & 40.0 & 4 & 50 & 16 & 42.1 \\
\hline & degree & & 0.0 & 4 & 50 & 4 & 10.5 \\
\hline \multirow[t]{3}{*}{ Work Experience } & $0-5$ years & 11 & 36.7 & & 0 & 11 & 28.9 \\
\hline & 6-10years & 11 & 36.7 & 4 & 50 & 15 & 39.5 \\
\hline & above 10 year & 8 & 26.7 & 4 & 50 & 12 & 31.6 \\
\hline
\end{tabular}

As can be seen in the above table, the principals who participated in the study are well experienced and composed of coming from different corners of Ethiopia with their lived experiences to get the insight to understand the bird's eye view on the current adult education practices in the country.

Out of 38 respondents $29(76.3 \%)$ of them were males while the remaining $9(23.7 \%)$ were females. In the entire respondent category, the numbers of males' respondents were greater than that of females.

With reference to age of the respondents the largest proportion of respondents that is $27(71.1 \%)$ were found among the age categories of 20-25 years. The remaining $9(23.7 \%)$ and $2(5.3 \%)$ were found among the age categories of 26-30 and above 30 years respectively. The majorities of respondents are not matured enough to facilitate and supervise according to adult learners need.

In term of educational qualification $18(47.4 \%)$ of respondents were grade 10 and 12 grade complete, $16(42.1 \%)$ of them were diploma graduates and the remaining $4(10.5 \%)$ of the total respondents were degree holders. This revealed that except those facilitators with low educational qualification the remaining respondents had good educational background to supervise, train and coordinate the implementation of the program.

The majority $15(39.5 \%)$ of facilitators were found among the service category of $6-10$ years while $12(31.6 \%)$ of FAL Facilitators, experts and supervisors were found among the service category of 10 and above years. Maturity and experience will make the implementation of functional adult literacy program effective if properly used.

Table 3: Enrollment, drop-out and completion data of FAL learners (1st Level)

\begin{tabular}{|l|l|l|l|l|l|l|l|l|l|l|}
\hline \multirow{2}{*}{$\begin{array}{l}\text { Academic } \\
\text { year }\end{array}$} & town & Registered & & Drop-out & \multicolumn{3}{|l|}{ Complete the academic year } \\
\hline \multirow{2}{*}{$2016 / 17$} & Robe & 270 & 300 & 570 & $227(84.1 \%)$ & $279(93.0 \%)$ & $506(88.8 \%)$ & $43(15.9 \%)$ & $21(7.0 \%)$ & $64(11.2 \%)$ \\
\cline { 2 - 10 } & Goba & 196 & 200 & 396 & $174(88.8 \%)$ & $185(92.5 \%)$ & $359(90.7 \%)$ & $22(11.2 \%)$ & $15(7.5 \%)$ & $37(9.3 \%)$ \\
\cline { 2 - 11 } & Total & 466 & 500 & 966 & $401(86.1 \%)$ & $464(92.8 \%)$ & $865(89.5 \%)$ & $65(13.9 \%)$ & $36(7.2 \%)$ & $101(10.5 \%)$ \\
\hline \multirow{2}{*}{$2017 / 18$} & Robe & 512 & 620 & 1132 & $457(89.3 \%)$ & $590(95.2 \%)$ & $1047(92.5 \%)$ & $55(10.7 \%)$ & $30(4.8 \%)$ & $85(7.5 \%)$ \\
\cline { 2 - 10 } & Goba & 371 & 432 & 803 & $334(90.0 \%)$ & $420(97.2 \%)$ & $754(93.9 \%)$ & $37(10.0 \%)$ & $12(2.8 \%)$ & $49(6.1 \%)$ \\
\cline { 2 - 10 } & Total & 883 & 1052 & 1935 & $791(89.6 \%)$ & $1010(96.0 \%)$ & $1801(93.1 \%)$ & $92(10.4 \%)$ & $42(4.0 \%)$ & $134(6.9 \%)$ \\
\hline
\end{tabular}

From this data one can understood that the enrollment of functional adult learners increase from year to year, but the drop-out rate was beyond the expectation. In 2016/17 academic year, the drop-out rate of 1 st level functional adult learners was $88.8 \%$ Robe and $90.7 \%$ in Goba. Whereas, the completion rate in both towns was only $10.5 \%$.

In $2017 / 18$ academic year even though the number of registered adult learners' increases, the drop-out rate of 1 st level functional adult learners was increased to $93.1 \%$ and the completion rate extremely decreased to $6.9 \%$. In both towns females completion rate was very low than males. This reveals that, the practice of implementing FAL program was still a burning issue for Robe and Goba Towns education sectors. 
Table 4: Enrollment, drop-out and completion data of FAL learners (2nd Level)

\begin{tabular}{|c|c|c|c|c|c|c|c|c|c|c|}
\hline \multirow[t]{2}{*}{$\begin{array}{l}\text { Academic } \\
\text { year }\end{array}$} & \multirow[t]{2}{*}{ Town } & \multicolumn{3}{|c|}{ Registered } & \multicolumn{3}{|l|}{ Drop-out } & \multicolumn{3}{|c|}{ Complete the academic year } \\
\hline & & $\mathrm{M}$ & $\mathrm{F}$ & $\mathrm{T}$ & $\mathrm{M}$ & $\mathrm{F}$ & $\mathrm{T}$ & $\mathrm{M}$ & $\mathrm{F}$ & $\mathrm{T}$ \\
\hline \multirow{3}{*}{$2016 / 17$} & Robe & 122 & 211 & 333 & $98(80.3 \%)$ & $193(91.5 \%)$ & $291(87.4 \%)$ & $24(19.7 \%)$ & $18(8.5 \%)$ & $42(12.6 \%)$ \\
\hline & Goba & 98 & 101 & 199 & $81(82.7 \%)$ & $88(87.1 \%)$ & $169(84.9 \%)$ & $17(17.3 \%)$ & $13(12.9 \%)$ & $30(15.1 \%)$ \\
\hline & Total & 220 & 312 & 532 & $179(81.4 \%)$ & $281(90.1 \%)$ & $460(86.5 \%)$ & $41(18.6 \%)$ & $31(9.9 \%)$ & $72(13.5 \%)$ \\
\hline \multirow{3}{*}{$2017 / 18$} & Robe & 176 & 198 & 374 & $153(86.9 \%)$ & $179(90.4 \%)$ & $332(88.8 \%)$ & $23(13.1 \%)$ & $19(9.6 \%)$ & $42(11.2 \%)$ \\
\hline & Goba & 158 & 200 & 358 & $139(88.0 \%)$ & $179(89.5 \%)$ & $318(88.8 \%)$ & $19(12.0 \%)$ & $21(10.5 \%)$ & $40(11.2 \%)$ \\
\hline & Total & 334 & 398 & 732 & $292(87.4 \%)$ & $358(89.9 \%)$ & $650(88.8 \%)$ & $42(12.6 \%)$ & $40(10.1 \%)$ & $82(11.2 \%)$ \\
\hline
\end{tabular}

As shown in the table, enrollment rate of adult learners increase from year to year, but the drop-out rate was beyond the expectation like 1st level. The drop-out rate of $2^{\text {nd }}$ level adult learners was in 2016/17 and 2017/18 was respectively $(86.5 \%)$ and $(88.8 \%)$ which is increased by $2.3 \%$. In the same table, the completion rate of $2016 / 17$ and $2017 / 18$ were respectively (13.5\%) and (11.2\%). This is decreased from year to year. This reveals that, the educational wastage was very high. In both towns the completion rate of women was relatively lower than male adult learners.

Graphic Representation Level 1 +level 2 Adult learners in Robe and Goba Towons

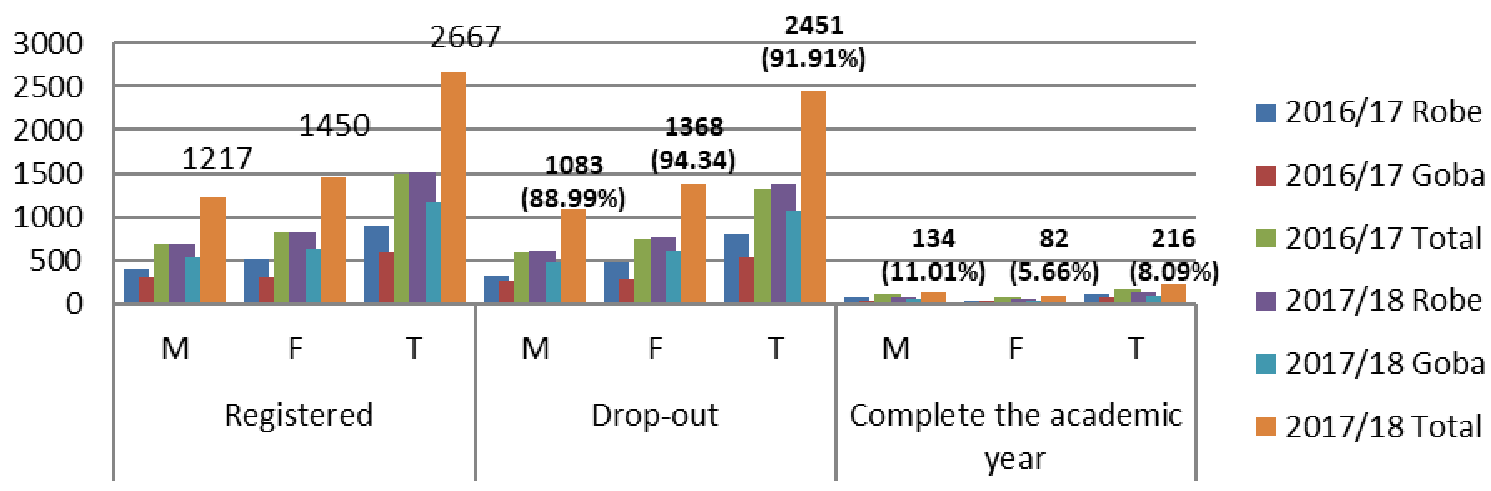

Figure 1: Graphic representation of $(1 \mathrm{st}+2 \mathrm{nd}$ level) adult learners' enrollment, drop-out and completion rate data:

Figure 1 show that, the total drop-out rate of $(1 \mathrm{st}+2 \mathrm{nd}$ level $)$ was $(91.91 \%)$. This is beyond the expectation. Whereas, the total completion rate extremely decreased to $(8.09 \%)$. Particularly, female completion rate $(5.66 \%)$ was very low as compared to male completion rate (11.01\%).

Table 5: The practices of functional adult literacy program

\begin{tabular}{|c|c|c|c|c|c|c|c|}
\hline \multirow[t]{2}{*}{ No } & \multirow[t]{2}{*}{ Items } & & \multicolumn{5}{|c|}{ Facilitators } \\
\hline & & 1 & 2 & 3 & 4 & 5 & fm \\
\hline 1 & Consideration given to the selection of facilitators & 5 & 13 & 12 & & & 2.33 \\
\hline 2 & Pre-work training on the method of training FAL & 12 & 12 & 6 & & & 1.8 \\
\hline 3 & Extent of need assessment made to facilitate FAL & 7 & 11 & 12 & & & 2.17 \\
\hline 4 & Adult learners practice and decision making level & 8 & 10 & 12 & & & 2.12 \\
\hline 5 & $\begin{array}{l}\text { The effort made education office to make teaching learning } \\
\text { more practical and flexible }\end{array}$ & 3 & 6 & 6 & 9 & 6 & 3.3 \\
\hline
\end{tabular}

N.B: $5=$ Very high, $4=$ High, $3=$ Medium, 2 = Low, $1=$ Very low

Note: level of performance mean value 1.50 - 2.49 weak performance, 2.50 - 3.49 medium performance, 3.50 4.49 high performance, and 4.50 and above very high performance.

As indicated in Table 5, items 1-4 above; the mean value was found to be below the average which indicates weak performance. That means, in both towns, there was no trends of selection of facilitators, pre-work training on the method of training FAL, no need assessment made to facilitate FAL and there was not practice of adult learners to decide when, where and what to learn at all. According to majorities of experts and supervisor interviewees, instead of selecting a new man power as facilitator, it is more preferable to use teachers, health and agriculture extension workers as a facilitator.

Both Expert A and Supervisor A explained that: 
"Newly deployed facilitators were given 5 to 10 days training. In addition, 10 days pre-work training was given for facilitators selected from teachers and healthy workers on the method of teaching FAL before the class starts."

Document such as training attendance, payroll copy and training manuals found in both town Education offices, confirm that, 6 days pre-work training was given by Robe TTC to newly hired facilitators and formal teachers. However, according to DVV(2011), training should be carried out at least for 10 days

Concerning the effort made education office to make teaching learning more practical and flexible; the mean value was 3.3 which indicate medium performance. The response gathered through interview also shows FAL program in Goba and Robe towns were carried out adult education guidelines. However, decisions made by adult learners are not acceptable

The management of functional adult literacy program

Therefore, fulfillment of educational materials and teaching aids play an important role in keeping skill training, quality and implementation of literacy program. (Tekalign Minalu. 2010)

Table 6: Managing practice of functional adult literacy program

\begin{tabular}{|l|l|l|l|l|l|l|l|}
\hline No & Items & \multicolumn{3}{|c|}{ Facilitators } \\
\cline { 3 - 7 } & & $\mathbf{1}$ & $\mathbf{2}$ & $\mathbf{3}$ & $\mathbf{4}$ & $\mathbf{5}$ & $\mathbf{f m}$ \\
\hline 1 & Level of planning to implement FAL program & & 2 & 11 & 8 & 9 & 3.80 \\
\hline 2 & monitoring and evaluation ability of FAL program & 2 & 4 & 6 & 11 & 7 & 3.60 \\
\hline 3 & Level of institutional support in FAL program & 8 & 6 & 9 & 3 & 4 & 2.63 \\
\hline 4 & Extents to which adult learners awarded about FAL program. & 10 & 8 & 8 & 4 & & 2.20 \\
\hline 5 & level of sectors engagement in the implementation of FAL program & 12 & 8 & 10 & & & 1.93 \\
\hline
\end{tabular}

As indicated in Table 6, items 1 and 2 above; the mean value were respectively 3.80 and 3.60 which indicate that, planning, monitoring and evaluation abilities were found to be at good.

2 Education experts and 2 supervisor interviewees explained that:

"In Woreda and FAL centers, we have human powers that have an ability of planning monitoring and Evaluation. However, the problem of implementing FAL program is not solved as per the government guiding principles"

"But, one of expert interviewee of Goba Education office explained as they have problems on FAL program monitoring and evaluation. According to him, they only know how to evaluate and monitor formal education system. They need more training and guideline to evaluate Adult learners."

In the same table of item 3 above; the mean value was 2.63 which indicate to some extent, there was institutional support in functional adult literacy program. Interviewees elaborate institutional support as:

"We support FAL centers with materials such as: boards, chalks, manuals and teacher guides. But, our support is not continuous. Our focus is only on material support. Still we didn't focus on technical support. If condition is fulfilled, we proposed to help facilitators through capacity building".

In item 5 of the same table above; there was low level of sectors engagement in the implementation of FAL program. The mean value was found to be 1.93. Engagement of other sectors in FAL program was not carried out according to the national adult education strategy. Literacy and Adult Education (Labe) Uganda Report of the Final Evaluation prepared by Warren Nyamugasira (2005) confirm the result obtained on the engagement of concerned sectors. Moreover, the response gathered through interview confirmed the above idea that, there were gap in building partnership with other sectors to implement FAL program.

Table 7: Challenges to implementing Functional Adult literacy program

\begin{tabular}{|c|c|c|c|c|c|c|c|}
\hline & \multirow[t]{2}{*}{ N0 Items } & \multicolumn{6}{|c|}{ Facilitators } \\
\hline & & 1 & 2 & 3 & 4 & 5 & fm \\
\hline 1 & Facilitators unable to identified their duties and responsibilities & & & 6 & 6 & 16 & 4.07 \\
\hline 2 & There are lacks Trained man powers in area of functional adult literacy & & & 4 & 9 & 17 & 4.43 \\
\hline 3 & Lack of managing FAL program with planned activities & & 2 & 4 & 9 & 15 & 4.10 \\
\hline 4 & $\begin{array}{l}\text { Facilitators have a gap to identify adult learners according to their ability } \\
\text { and need }\end{array}$ & 9 & 6 & 8 & 2 & 5 & 1.93 \\
\hline 5 & problem accountability and responsibility to implement FAL program & & & 9 & 9 & 12 & 4.10 \\
\hline 6 & Budgets are not allocated to implement FAL program & & & & 9 & 21 & 4.7 \\
\hline 7 & $\begin{array}{l}\text { Kebele Boards and technical committee have not participated according to } \\
\text { schedules }\end{array}$ & & & & 4 & 26 & 4.87 \\
\hline 8 & No attention could be given by Education office to FAL program & & 4 & 6 & 10 & 10 & 3.60 \\
\hline
\end{tabular}

N.B: $5=$ Strongly Agree, $4=$ Agree, $3=$ Undecided, $2=$ Disagree, $1=$ Strongly Disagree

Note: level of performance mean value 1.50 - 2.49 strongly disagree, 2.50 - 3.49 Undecided performance, 3.50 4.49 Agree, and 4.50 and above strongly agree.

The mean value of items $1,2,3,5,6,7$ and 8 of above table were found between $3.50-4.49$ and above 
which indicate that, in Both Goba and Robe towns, still problems of implementing Functional Adult literacy program are not solved. The result revealed that, Facilitators unable to identified their duties and responsibilities; there are lack of trained man powers in area of functional adult literacy and lack of managing FAL program with planned activities. In addition, there were accountability and responsibility problems to implement FAL program; Budgets were not allocated to implement FAL program; Kebele Boards and technical committee have not participated according to schedules and attention could not be given by Education office to FAL program.MOE, (2010:46) reports in Abebe Anjulo (2017) emphasized the same result.

Similarly, 6(75\%) of interviewees explained that,

"The newly hired facilitators have problems of identifying their duties and responsibilities; education sectors still didn't have adult education graduate. As a result, they have lack of managing FAL program with planned activities."

Particularly, 2 experts from Robe and 1 supervisor from Goba strictly underlined that,

"There is no budget at all. Adult education board and technical committee were established from woreda to training centers. But, we haven't seen their participation. There are no follow-up mechanisms. No one need to take accountability and responsibility to implement FAL program attention could not be given by Education office and all other concerned sectors to FAL program. Therefore issues of FAL program need more attention in Robe and Goba Towns of Bale Zone"

With regards to item 4 of the same table, the averages mean value of "Facilitators have a gap to identify adult learners according to their ability and need" was 1.93. This indicates that, facilitator respondents disagreed to the idea. However, the result obtained from interviewees was contradicted with that of facilitators.

For instance, three experts ( 1 from Robe and 2 from Goba) education sectors explained that:

"Even though short term training was given to facilitators, still the ways they facilitate, guide and help adult learners are not interested. They can't identify even slow, medium and high adult learners. Schedules are not prepared according to needs of adult learners."

Similarly (2 supervisors of Robe towns) explained their idea as follows:

"Facilitators are not in position to help adult learners. They spent a lot of time on teaching formal school students. Most facilitators didn't need to apply what they have trained. Instead, they need to leave.

In both Goba and Robe towns, adult learners registration lists, attendances and day today follow up checklists showed that, facilitators activities on implementing Functional adult literacy program and identifying learners according to need and their abilities are found to be unsuccessful. Review of international literature revised by Linda Leach, Nick Zepke, Penny Haworth, Peter Isaacs, William Nepia (2009) on Organizational factors that affect delivery of adult literacy confirm the ideas of interviewees on facilitators ability and need assessment.

\section{Conclusions}

Based on the empirical data and the findings of the study the following conclusions have been drawn: Even if functional Adult literacy program started earlier, in Robe and Goba towns most respondents of this study are unsuccessful on practice of implementation of functional adult education in Goba and Robe towns.

From the finding it is possible to conclude that the selection and training of facilitators, the flexibility of the program, need assessment, planed activities related to adults' day to day activities, monitoring and evaluation, community participation and awareness created about FAL program were not carried out according to the principles and guide lines of FAL program. From the finding it is also concluded that, there are a managing problems. Moreover, the findings also disclose that, there are lack of responsibility and accountability. Budgets are not allocated to implement FAL program; Kebele Boards and technical committee have not participated according to schedules. Generally, attention could not be given by Education office to implement Functional Adult Literacy program according to government policy and strategies. Besides, it is also further concluded that, facilitators' activities on implementing Functional adult literacy program and identifying learners according to need and their abilities are found to be unsuccessful

\section{Recommendation}

To make the practice of implementing Functional Adult Literacy successful the following things must be done in both Robe and Goba towns of Bale Zone as based on the findings of the study. Facilitating, supervising, training need assessment practices should be reorganized according to guideline. Problems of managing functional adult literacy program should be minimizing through, on the work training and capacitating concerned bodies. Challenges related to: Selection and training of facilitators, the flexibility of the program, monitoring and evaluation, responsibility and accountability, budgets should be solved

Boards and technical committee should be participated according to schedules. More importantly, attention should be given by Education office to implement Functional Adult Literacy program according to government 
policy and strategies. In addition to these, Robe and Goba town kebeles and their respective training centers need to have an established system of recruitment of adult learners, staffing, resourcing, financing, mobilization, delivery, monitoring and evaluation of adult education.

\section{Acknowledgments}

Researchers would like to thank Robe and Goba town experts' supervisors and facilitators who actively participated in the study in sharing their experiences and outlooks on the practice of implementing Functional Adult Literacy program on the study area.

\section{Conflict of Interest}

The researchers would like to declare there is no conflict of interest in this research authorship. In case, if anyone claims co-authorship the current researchers would take the full responsibility for any measure.

\section{Reference}

DVV,(2011) Adult Education and Development Non-Formal Skills Training Adult Education for Decent Jobs and Better Lives. Inistitute for internationale zusammenarbeit des Deutschen Vokshochschul-Verbandes. Federal ministry for Economic cooperation. Addis Ababa.

Genet Gelana 2014 An Assessment of Ethiopia's Progress towards Attaining Integrated Functional Adult Literacy Email: genetgelana@yahoo.com Bahir Dar University

John Creswell (2008), Planning, Conducting, and Evaluating Quantitative and Qualitative Research: Educational Research. Fourth Edition University of Nebraska-Lincoln Boston Columbus

Kifle Bidika (2016) An Investigation on the Practice of Integrated functional Adult Literacy in Benishangul Gumuz Region Wolaita Sodo University Global Journal of HUMAN-SOCIAL SCIENCE: Linguistics \& Education Volume 16 Issue 7 Version 1.0 ISSN: 2249-460x \& Print ISSN: 0975-587X

Linda Leach, Nick Zepke, Penny Haworth, Peter Isaacs, William Nepia (2009) Organizational factors that affect delivery of adult literacy, language and numeracy provision A review of international literature. College of education Massey University

Mari Yasunaga, UNESCO (2014) Non-Formal Education as A Means to Meet Learning Needs of Out-of-School Children and Adolescents; Out of school children initiative.

Rahel Gashaw 2014 Quality of Early Childhood Care and Education: The case of selected Government ECCE centers in Bole and Kirkos Sub-cites in Addis Ababa, Ethiopia A Thesis Submitted to Institute of Educational Research Addis Ababa University

Samuel Asnake (2012), Linking Functional Adult Literacy (FAL) within Poverty Reduction Interventions: Potentials and Prospects in Ethiopia. Parallel Session 7: Organized by Institute of Education and Professional Development, Jimma University

Sandhaas, Bernd (2009) Portrait adult education Ethiopia. Addis Ababa : dvv international 2009, IX, 137 S. (Internal Paper; 76) - URN: urn:nbn:de:0111-pedocs-109147. Addis Ababa. Empfohlene Zitierung/ Suggested Citation:

Sisay \& Yilfashewa (2017) Integrated Functional Adult Literacy: Existing Practices and Challenges in Eastern Ethiopia. International Journal of Education \& Literacy Studies ISSN: 2202-9478 www.ijels.aiac.org.au Haramaya University, Ethiopia,

Tadesse Abera (2019) Evaluation of the National Adult Education Strategy Implementation Success: The Case of University Trainee Issues in different Regions of Ethiopia Journal of Equity in Science and Sustainable Development University of Gondar E-mail: peace4ujesus@gmail.com Vol. 3(2):136-146 Article Number: JESSD22.3.2019 ISSN 2523-1901(Online) URL: http://jessd.mwu.edu.et/index.php/jessd

Tekalign Minalu ( 2010) The Practices in The Management of Community Skill Training Centers In Selected Woredas of Iluababor Zone of Oromia Regional State. Unpublished thesis Degree of Master of Education. Addis Ababa.

Usman, Yunusa Dangara (2015) The Impact of Instructional Supervision on Academic Performance of Secondary School Students in Nasarawa State, Nigeria Journal of Education and Practice www.iiste.org ISSN 2222-1735 (Paper) ISSN 2222-288X (Online) Vol.6, No.10, 160

Warren Nyamugasira (2005) Literacy and Adult Education (Labe) Uganda Report of the Final Evaluation of "Literacy and Continuing Education in Uganda 2000-2005" and "Family Basic Education in Uganda" 20032005 Programs

Abebe Anjulo (2017), Factors Affecting the Successful Enrollment and Participation of Adult Learners in Kindo Koysha Woreda of Wolaita Zone,Snnprs. International Journal of African and Asian Studies www.iiste.org ISSN 2409-6938 An International Peer-reviewed Journal Vol.29, 2017. Hawassa, Ethiopia 